\title{
Assessment of the Students' Social Health Level in the Technical University Educational Environment in the South Yakutia Region
}

\author{
Ksenia Polkova \\ Technical Institute (branch) of \\ North-Eastern Federal \\ University, \\ Department of General Education \\ Neryungri, Russia \\ kpolkova@inbox.ru
}

\author{
Larisa Prokopenko \\ Technical Institute (branch) of \\ North-Eastern Federal \\ University, \\ Department of General Education \\ Neryungri, Russia \\ larisana4@mail.ru
}

\begin{abstract}
This paper is devoted to studying the students' social health. Entering the university, young people find themselves in new conditions of educational activity, new life situations, accompanied by the restructuring of the mental and physiological states. The rapid development of modern society, modern social and political challenges have imposed high requirements for health, aggravating the negative trends of social behaviour of young people. Considering the regional location features of the technical institute, the trends in university admissions of young people, the authors investigated the level of students' social health on the methodology developed by E.V. Tsikalyuk. It has shown that $2 / 3$ of the students have the average level of social health, but $1 / 3$ has a low level. Most students have no difficulty communicating, their relationships are harmonious and bear positive values. But "social adaptation" and "social activity" are at a low level among a large number of students, which indicates the lack of adaptation in the university environment and the reluctance to actively participate in various mass events and public life. As priority directions in social and educational university activities, the paper proposes to implement effective social protection of students and to increase their adaptation to the university environment at different levels: didactic, socio-psychological, professional, ethnic and cultural.
\end{abstract}

Keywords - university students, social health, social and pedagogical activity.

\section{INTRODUCTION}

Student youth is a carrier of high intelligence, intellectual capacity, labour resources for the social and economic development of the country.

As a special social group, it has characteristic features due to age, basic education, life organization, a shared focus on the acquisition of professional knowledge and skills.

Years of study at university is a period when some profound changes occur in the lifestyle, culture and psychology of young people. This is the period of forming the personality, social maturity, gaining a new social status.
As T.V. Sutyagina truly argues that this is the period of forming the worldview, defining its identity and uniqueness, this is the beginning of shaping attitudes to the age and an individual way of life. Individualization of social values and activity standards of relationship with other people, based on the individual position of the person, determines the development level of the subject of social relations. These are the relationship within student groups, their relationship with teachers, parents and themselves [1].

Entering the university, young people find themselves in new conditions of educational activity, new life situations, accompanied by the restructuring of the mental and physiological states. At the same time, they need to adapt to the new system of teaching (didactic level of adaptation) which differs from the school system. The increasing volume of information, the constant intensification of the students' work, the widespread introduction of new technical means into the learning process - are only a short list of factors that trigger the occurrence of psychosomatic diseases. Joining a new team, school or dormitory is accompanied by the intensification of intercultural interaction. It is known that adaptation at the socio-psychological level can occur in different ways: some people successfully cope with situations of intercultural interaction, others have difficulties in communicating. The professional level of adaptation is characterized by the acceptance of values of the future professional activity and a certain focus on them. At the same time, new conditions of students' activities within the university environment is a qualitatively different system of relations, responsibility, dependence, where the need for self-regulation of their own behaviour comes to the foreground, taking into account the level of freedom in the organization of personal activities and life which was unavailable to them before [1].

Difficulties in adaptation to university training can lead to psychophysiological discomfort, low academic achievements, maladaptive syndrome.

The rapid development of modern society imposes high requirements for people and their health. Modern people 
increasingly have to live on the limit, however, on the background of prolonged emotional and social stress. at the limit of their abilities and at the same time on the background of protracted psycho-emotional and social stress. The situation found in the Russian society is defined by Russian experts as "unstable", "critical", "sanctional" and marks a new negative trend. We observe changes in the students' motivation for the educational activity, reduction of their creative activity, deviations in their social behaviour. The trend towards increasing social instability is largely associated with increased social maladjustment and civil indifference of youth, widened scale and pace of spread of drug addiction and substance abuse, criminal and addictive behaviour [2].

In this connection, special importance is given to the problem of the social health of youth.

Considering health as a social category, it should be said that this phenomenon of the harmonious interrelations between the individuals and their social environment, an attitude to themselves and their place in the social structure, contributing to their health and optimal functioning in the social environment.

Numerous studies offer a variety of approaches to investigating social health.

In the context of the medical approach, it is an "optimally adequate social environment which prevents diseases caused by social conditions and social maladjustment and determines the state of social immunity and the harmonious development of the individual within the social structure" [3].

From the standpoint of a psychological approach (A. Adler, V.A. Ananiev, L.A. Baikova, S.V. Egorova, A. Maslow, G.S. Nikiforov and others), social health is studied in a symbiotic relationship with the spiritual and mental health. The representatives of this approach characterize the essence of social health through harmonious relationships with others, conformity of behaviour to social norms and cultural requirements.

Within a sociological approach (M. Weber, C.I. Grigoriev, I.V. Zhuravleva, M.B. Liga, V.A. Yadov, etc.), social health is understood as the behaviour of society members that does not violate public order, the result of socialization, acquiring and accepting social norms, values and patterns of behaviour.

The pedagogical value of "social health is a moral selfcontrol, a reasonable self-acceptance of Inner Self, personal self-identification in optimal social conditions of micro - and macro-environment (family, school, social group)" [3].

The social health of individuals in general and student youth separately were deeply investigated in the works by modern scientists (O.S. Vasilieva, I.M. Vorontsov, V.I. Kolesov, V.N. Maksimova, I.A. Nesterova, N.V. Sokratov, L.G. Tatarnikova, V. L. Filatov, V. Frankl, E.V. Tsikalyuk, etc.). The problem of the social health of youth is stated as one of the vital problems of modern society.

V.I. Kolesov relying on the concept of the world health organization proposes to evaluate the social health of students due to two main criteria: harmonious relationships between the individual and the social environment; social maturity of the individual [4].

The study by I.A. Nesterova emphasizes that "the basic idea of a conceptual foundation for the students' social healthcare within a higher educational institution is to identify the essential characteristics of the concept "social health", to consider the adaptative and anthropocentric standards of social health, the main principles and criteria of a healthy lifestyle in the light of these standards and the principles of social and pedagogical activities in the university aimed at promoting students' social health" [2].

The research by E.V. Tsikalyuk, showed that "in the framework of sociological knowledge, it becomes possible to consider the social health of student youth as an integral term reflecting the level of individual adaptation in the social environment, the degree of individual social activity, harmonious relationships with other people and social groups, behaviour regulation complying with the existing norms and universal values, a healthy lifestyle. The level of students' social health is determined due to the social functioning of this social group and the type of organizational university culture. The main criterion for allocation of the social functioning methods is the level of adaptation to the new social environment. In accordance with this criterion, prosociality can be characterized by a high level of adaptation, conformity - by conditional adaptation, inertness - by partial adaptation, asociality - by weak adaptation, antisociality - by maladjustment" [5].

In the framework of social and pedagogical university activities, modern researchers consider the issues of forming students' social health, offer different ways and models of education, assume creating a comfortable psychological educational environment. Psychologically comfortable and safe educational environment of the university is the guarantor of forming the social competence and orientations toward positive relationships within the given society and is also a fundamental prerequisite of adaptation. The educational environment promotes the creation of positive motivation for professional training, cognitive activity, formation of professional orientation, development of adequate self-acceptance. All this has a positive effect on successful learning and, ultimately, increases the efficiency of the higher education system. Thus, the more students are successful, the more well-trained highclass professionals are found in the country.

M.S. Petrova acknowledges the role of socialisation in educating university youth [6]. Socialization acts as a process and the result of learning and active reproducing individual social experience, carried out in communication and other activities [7]. Future specialists should be characterised by the formed social health, which is vital as teamwork is built on relationships with people, colleagues and other people around.

A.E. Nikiforov shows that forming the social health of students of pedagogical specialities is important in the context of their future professional activity [8]. This approach is undoubtedly necessary for students of any other professional qualification. 
E.V. Milkova, N.V. Belyaeva pays attention to the creation of necessary conditions for the successful adaptation of students from the indigenous minorities of Siberia and points out the necessity of taking into account the specificity of the university in which these students study. The inclusion of two components into the social and pedagogical activities are proposed: direct interaction with the person; mediation in maintaining the relationship between the person and the environment which enables personal socio-cultural formation and development [9].

Active development of the volunteer movement in the country is a prerequisite for the high social activity of young people. One of the directions of this movement includes providing support for people who need any assistance. Let us consider this direction from the standpoint of the sociopsychological approach. "You should pay attention to the importance of social support as a process and the result of interpersonal relationships because this support is a factor of individual psychological well-being and a condition for reducing the recipient's emotional distress, and thereby it resolves contradictions in distinguishing the interpretations of the assistance by someone who offers and provides the assistance, and someone who obtains it... A psychological attitude to the support is much easier to integrate into everyday practices of care and support in social work and socioeducational activities because this attitude is closer to the natural forms of organizing life in the family, small groups and communities" [10].

Undeniable interest is devoted to the vector of moods and models of the students' social behaviour which are formed under the influence of modern social and political challenges. The studies by E.A. Mikhailova and T.V. Cherkasova show that "the values orientations and attitudes of young people are formed under the influence of macroenvironment. This social group is the subject of social reproduction and dynamics. The analysis of the life strategies selected by the youth in a rapidly changing social space (taking into account regional specifics of residence) allows one to predict the trends of their development and to control processes in the youth environment" [11]. And that is encouraging to make conclusions "about the presence of a stable tendency to preserve traditional norms governing intergenerational relations in the Republic of Bashkortostan: the students' attitudes in the region are characterized by the stable social guidelines based on the traditional mentality and adequately reflect the Russian reality" [11].

We would like to dwell on the relationship between education, labour market and social behaviour. L.D. Konstantinovsky wrote that "the labour market is closely and inextricably linked to the education system and social behaviour of young people due to their choice of educational and professional career: the labour market receives reinforcements from the sphere of education (from primary schools to universities); this process due to the competency of young people affects their social behaviour, their own choice of educational and professional careers. Considering the role of education, it is important to keep in mind the following: the education system should prepare not the well-machined gears for the economic mechanism, which was acceptable in the earlier economy, but a modern worker who possesses a set of qualities providing the ability to function in the conditions of a complex society, high-tech industries, dynamic labour market and changing circumstances of social life" [12].

Particular importance in modern conditions of higher education is given to a socio-pedagogical activity aimed at forming the students' social health, which along with the professional levels is among the indicators of preparing highqualified specialists. These indicators are crucial for the successful social functioning of both the young people themselves and the state as a whole.

We believe it is important to examine the social health level of students living and studying in the South Yakutsk region, taking into account the regional North location of the university, admissions trends and modern socio-political realities.

Neryungri Technical Institute (branch) of North-Eastern Federal University (TI (b) NEFU) is located in the Republic of Sakha (Yakutia). In connection with the increased opportunity for students to enrol universities on USE and to study in the Central and Siberian regions of the country that have more favourable climate and developed infrastructure, we witness an outflow of young people from South-Yakutsk region in the past decade. But there is an influx of young people from more Northern regions, especially from rural areas, who poorly speak Russian. Over the past five years, up to $50-70 \%$ of the total number of students enrolled in the institute are represented by indigenous peoples of Yakutia. Young people experience challenges of adaptation in general and the communicative approach in particular. As a result, by the end of the first year, there is found a large number of student expulsion in the technical institutions which reaches 30-40\%. At present, there is also another trend - the enrolment of girls (up to $40-50 \%$ in a study group) in such technical specialities as "Open-pit mining", "Underground mining operations".

\section{MATERIALS AND METHODS}

The purpose of the study is to assess the students' social health level in the conditions of the technical university educational environment in the South Yakutia region.

The tasks are:

1. To estimate the level of social health of student youth arranged by individual components, in general by the university and by years.

2. To develop priorities for students' adaptation to the social and pedagogical activity in technical universities.

The research involved the full-time students who study in the 1st-3rd years in TI(b)NEFU. The total number of respondents was 109 people (62 males and 47 females). A questionnaire survey was conducted in 2018. We offered to answer the questionnaire "Students' social health" and to carry out calculations according to the method developed by E.V. Tsikalyuk [13]. The questionnaire consists of 5 sections (blocks), each including 5 questions. The sections represented the individual components of social health: 1) social adaptation; 2) relationship with others; 3) social activity; 4) attitude to social norms; 5) value orientations. By calculating 
the coefficient of the social health level, we determined the social functioning method of each student as well as of the examined group as a whole, based on the percentage of these methods and corresponding levels of social health in the university (Table I).

TABLE I. THE COEFFICIENT OF THE SOCIAL HEALTH LEVEL

\begin{tabular}{|l|l|l|}
\hline $\begin{array}{c}\text { The coefficient of } \\
\text { the social health level }\end{array}$ & \multicolumn{1}{|c|}{$\begin{array}{c}\text { The type of } \\
\text { social functioning }\end{array}$} & \multicolumn{1}{|c|}{$\begin{array}{c}\text { The level of } \\
\text { social health }\end{array}$} \\
\hline $1.5 \ldots 2$ & Prosociality & High \\
\hline $0.5 \ldots 1.4$ & Conformity & Average \\
\hline$-0.4 \ldots 0.4$ & Inertness & Low \\
\hline$-1.4 \ldots-0.5$ & Asociality & Social ailments \\
\hline$-2 \ldots-1.5$ & Antisociality & Social disease \\
\hline
\end{tabular}

\section{RESULTS AND DISCUSSION}

The results of the students' social health level arranged by each component separately are presented in Table II below.

TABLE II. ASSESSMENT OF THE STUDENTS' SOCIAL HEALTH LEVELS ARRANGED BY INDIVIDUAL COMPONENTS

\begin{tabular}{|c|c|c|c|c|c|}
\hline \multirow[b]{2}{*}{$\begin{array}{c}\text { The } \\
\text { coefficient of } \\
\text { the social } \\
\text { health level }\end{array}$} & \multicolumn{5}{|c|}{ Number of people, $\%$} \\
\hline & 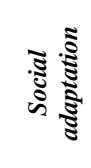 & 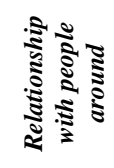 & 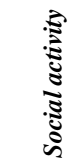 & 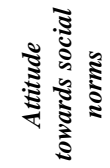 & 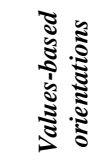 \\
\hline $1.5 \ldots 2$ & 4 & 23 & 3 & 6 & 32 \\
\hline $0.5 \ldots 1.4$ & 55 & 61 & 47 & 77 & 42 \\
\hline$-0.4 \ldots 0.4$ & 41 & 15 & 44 & 15 & 24 \\
\hline$-1.4 \ldots-0.5$ & - & 1 & 6 & 2 & 2 \\
\hline$-2 \ldots-1.5$ & - & - & - & - & - \\
\hline
\end{tabular}

The results of this study are important to note that the highest level of social health is found in the components "relationship with people around" and "values-based orientations". Thus, most students have no difficulty communicating, their relationships are harmonious and bear positive values. However, the emphasis is given to the facts that "social adaptation" and "social activity" are low among a large number of students, $41 \%$ and $44 \%$, respectively, falling into the category of "inertness". That is, this part of students is not well adapted to the university environment and does not actively participate in various cultural and sports events and public life. The overall results of the social health levels can be seen in Table III.

TABLE III. ASSESSMENT OF THE SOCIAL HEALTH LEVELS IN THE INSTITUTE ON THE WHOLE

\begin{tabular}{|l|l|l|}
\hline $\begin{array}{c}\text { The coefficient of the } \\
\text { social health level }\end{array}$ & \multicolumn{1}{|c|}{$\begin{array}{c}\text { Number of } \\
\text { people, } \%\end{array}$} & \multicolumn{1}{|c|}{$\begin{array}{c}\text { The level of } \\
\text { social health }\end{array}$} \\
\hline $1.5 \ldots 2$ & 0.9 & High \\
\hline $0.5 \ldots 1.4$ & 79 & Average \\
\hline$-0.4 \ldots 0.4$ & 19.2 & Low health level \\
\hline$-1.4 \ldots-0.5$ & 0.9 & Social ailments \\
\hline$-2 \ldots-1.5$ & - & Social disease \\
\hline
\end{tabular}

The results indicate the social health of the research participants in general, antisociality is missing here. But, mostly, the responses of the respondents (79\%) include conformist attitudes and a pretty large number of them (19.2\%) are characterised by inertness, which means a low level of social health. Though the high level of social health and prosociality occur quite rare $(0.9 \%)$. In accordance with this, the level of the students' social health at TI(b)NEFU can be estimated as average with the predominance of the conformal type of social functioning and manifestations of inertness. Next, we were interested in studying the level of social health arranged by years (Table IV).

TABLE IV. THE LEVEL OF STUDENTS' SOCIAL HEALTH ARRANGED BY YEARS

\begin{tabular}{|c|c|c|c|}
\hline \multirow{2}{*}{$\begin{array}{c}\text { The coefficient of } \\
\text { the social health level }\end{array}$} & \multicolumn{3}{|c|}{ Number of people, \% } \\
\hline & $\begin{array}{c}1 \text { year } \\
(n=44 \text { persons })\end{array}$ & $\begin{array}{c}2 \text { year } \\
(n=40 \text { people })\end{array}$ & $\begin{array}{c}3 \text { year } \\
(n=25 \text { people })\end{array}$ \\
\hline $1.5 \ldots 2$ & 2 & - & - \\
\hline $0.5 \ldots 1.4$ & 75 & 77.5 & 76 \\
\hline$-0.4 \ldots 0.4$ & 23 & 20 & 24 \\
\hline$-1.4 \ldots-0.5$ & - & 2.5 & - \\
\hline$-2 \ldots-1.5$ & - & - & - \\
\hline
\end{tabular}

These results show that the level of students' social health from year to year does not change obviously, it is mainly estimated as average among $2 / 3$ of respondents and as low among $1 / 3$ of students. To create conditions for forming the social health of a young student, it is necessary to develop the priority directions of socio-pedagogical activities in a higher educational institution which are aimed at developing and communicating such values as social cohesion and cooperation, initiative and activity, flexibility and adaptability, respect for social norms and traditions, interaction with Russian speaking representatives.

Bearing in mind the different types of adaptation (academic, socio-psychological, ethno-cultural, professional, pedagogical, social welfare), the socio-educational activities within a technical university to arrange adaptation of students, including the representatives of indigenous peoples of the Sakha Republic (Yakutia), are recommended to include:

1) creation of optimal environmental conditions, a psychologically comfortable and safe educational environment within the university;

2) organization of the educational process which does not allow any learning overloads based on individual capabilities of students and provides availability of teaching staff for consultations;

3) specific support and assistance in adapting students, coming from remote areas and living in the dormitory, to the new university conditions and accommodation, including certain support provided by senior students;

4) encouragement to self-motivation and self-expression in the new environment, stimulation of independence, reflexivity and activity in personal development;

5) provision of socio-psychological and pedagogical assistance to those who are in difficult life circumstances by using a helpline and meeting the educational psychologist; 
6) provision of training for tutors and parents how to prevent maladjustment and to overcome its consequences;

7) development of action plans: cultural, sports, volunteering, that can base on the traditions of the peoples of the North and widely involve the students.

\section{CONCLUSIONS}

Summarizing the results of the study, it can be noted that students of the technical universities, located in the South Yakutsk region, have mostly the average level of social health, but $1 / 3$ of these young people have a low level. In general, most students have no difficulty communicating, their relationships are harmonious and bear positive values. But "social adaptation" and "social activity" are at a low level among a large number of students, which indicates the lack of adaptation in the university environment and the reluctance to actively participate in various mass events and public life.

Social and pedagogical activity within the university should be aimed at the quality training of well-skilled specialists and the high social health of students. The training should be supported by monitoring the level of enrolee's social health and creating the conditions to develop their social values. The priority directions of university activities should include the implementation of effective social protection of students and the activity to increase their adaptation to the university environment at different levels: didactic, socio-psychological, professional, ethno-cultural, which will improve the social status of students and positively affect the quality of their studies and their further professional activities.

\section{REFERENCES}

[1] T.V. Sutyagin, "Forming the students' social experience at the initial stage of studying at university", Synopsis of the PhD thesis, Kostroma state university named after N.A. Nekrasov, Kostroma, Russia, 2007.
[2] I.A. Nesterov, "Conceptual framework of students' social healthcare", in Proceedings of the Izvestia of Samara Scientific Center of the Russian Academy of Sciences, vol. 14, No. 2 (3), pp. 626-628, 2012.

[3] "Modern technologies of preserving and strengthening of children's health", The textbook under the general editorship of N.V. Sokratova, Moscow, TC Sfera, 2005, 224 p.

[4] V.I. Kolesov, "Students' social health", in Bulletin of Saint-Petersburg University of MIA of Russia, No. 2 (42), pp. 217-229, 2009.

[5] E.V. Tsikalyuk, "Forming social health of student youth in the conditions of the organizational university culture", Synopsis of the $\mathrm{PhD}$ thesis, Zabaikalsky State Humanitarian Pedagogical University named after N.G. Chernyshevsky, Chita, Russia, 2012.

[6] M.S. Petrova, "Animation activities as a means of university students' social education", Synopsis of the $\mathrm{PhD}$ thesis, Kostroma state university named after N.A. Nekrasov, Kostroma, Russia, 2007.

[7] "The world of psychology. Psychological dictionary", URL: http://psychology.net.ru/dictionaries/psy.html?word=923.

[8] A.E. Nikiforov, "The problem of forming social health of the students of pedagogical specialities while teaching physical culture in the university", in Problems of modern pedagogical education, No. 44-1, pp. 167-172, 2014

[9] E.V. Milkova, and N.V. Belyaeva, "Adaptation of students from the indigenous minorities of the North, Siberia and the Far East in sociopedagogical activities KemSUCA", in Bulletin of Kemerovo State University of Culture and Arts, No. 4, pp. 103-109, 2010.

[10] D.V. Lifintsev, A.B. Serykh, and A.A. Lifintseva, "Social support as a psychological phenomenon", in Voprosy psikhologii, No. 5, pp. 105117, 2014.

[11] E.A. Mikhailova, and T.V. Cherkasova, "Motivation and values-based orientations of students in current socio-political realities (on the example of the Republic of Bashkortostan)", in Sociological journal, vol. 21, No. 2, pp. 51-67, 2015, DOI: https://doi.org/10.19181/socjour.2015.21.2.1320.

[12] D.L. Konstantinovsky, "Education, labour market and social behaviour of youth", In Sociological Journal, vol. 0, No. 3, pp. 55-69, 2014, DOI: https://doi.org/10.19181/socjour.2014.3.512.

[13] E.V. Tsikalyuk, "Methods of assessing the level of social health of student youth", in Bulletin of Transbaikal State University, No. 5, pp. 87-92, 2013. 